"Schоч. M. (1984) Recent developents in lithium treatment and research. In Current Trends in Lithium and Rubidium Therapy (ed. G. U. Corsini). Lancaster: MTP Press.

Ylesen. O. V. (1983) The effect of potassium on some nephrotoxic actions of lithium in rats. Danish Medical Bulletin, 31, 270-82.

"THOMSEN. K. (1984) Lithium clearance: a new method for determining proximal and distal tubular reabsorption of sodium and water. Nephron, 37, 217-23.

"SchоU. M. (1984) From mine to mind: Lithium in psychiatry. International Medicine, 4, 24-6.
12Leppik. 1. E. et al (1978) Lancet, 14 October. 849.

${ }^{13}$ Schou, M. (1984) Reply to Rogers. Psychosomatics, 25, 242.

14Schou. M. (1983) Lithium Treatment of Manic Depressive Illness: A Practical Guide. Karger Publications.

15YANG. Y. Y. (1985) The prophylactic efficacy of lithium and its effective plasma levels in Chinese bipolar patients. Acta Psy. chiatrica Scandinavica. 71, 171-5.

105CHOU, M. (1959) Therapeutic and toxic properties of lithium. In Neuropsychopharmacology. (eds. P. B. Bradley, P. Deniker and C. Radouco-Thomas). Amsterdam: Elsevier.

\title{
The Mental Health Act 1983-Second Opinions under Section 58
}

\section{Treatment with Electroplexy or Extended Medication}

\section{G. E. Langley, Consultant Psychiatrist and Mental Health Act Commissioner, Exminster Hospital, Exminster, Exeter}

Section 58 of the Mental Health Act 1983 provides for statutory control of certain treatments given to detained patients through an obligation to obtain their consent or secure the approval of a doctor called as a second opinion through the Regional Office of the Mental Health Act Commission.

To control, in this way, the treatment offered by a consultant to patients detained under his care is, in England and Wales, a new venture in both clinical practice and law. Described here are some of the patients seen by the second opinion doctors in the early days of these procedures and the problems encountered.

The treatments concerned are (a) electroplexy and (b) 'the administration of medicine to a patient by any means at any time during a period for which he is liable to be detained as a patient ... if three months or more have elapsed since the first occasion in that period when medicine was administered to him by any means for his mental disorder.' Other treatments may, in the future, be specified by regulation at the discretion of the Secretary of State.

If the patient understands the nature, purpose and likely effects of the treatment and consents to it, then the responsible medical officer (RMO), normally a consultant psychiatrist, certifies that this is so and the treatment proceeds.

If the RMO cannot certify that the patient is capable of understanding the treatment, or if the patient refuses the treatment, then the RMO must seek a second opinion through one of the three regional offices of the Mental Health Act Commission and a consultation is arranged with a doctor previously approved by the Commission for the purpose. Every effort is made to arrange the consultation within two days when the treatment is electroplexy and within one week for medication. Meanwhile, if treatment is required urgently it can be given if it falls within the provisions of Section 62 of the Act. Other treatments not covered by Section 58 may be given (under Section 63) on the direction of the RMO.

At the consultation the RMO and the visiting approved doctor (AD) confer and the AD must also confer with two other persons who have been professionally concerned with the care of the patient, one of whom shall be a nurse, and one neither a doctor nor a nurse.

If the RMO and the AD agree, then a certificate is issued stating that, notwithstanding the incompetency or refusal of the patient, the treatment should be given. Alternatively, the $A D$ may feel that the patient does comprehend the treatment and consent to it and he may then himself so certify. In the event of the RMO and the AD failing to agree, then the treatment may not be given until it is modified and agreement finally reached.

After the consultation a brief report is sent to the regional office of the Commission by the AD. This report has been used as the data base for the present study.

If it is wished to go beyond the remit of the original certificate the procedures have to be repeated. If the period of detention is renewed the RMO must send a report to the Commission and this report is reviewed by the approved doctor who provided the preceding certificate.

\section{Implementation}

The Mental Health Act 1983 came into force on 30 September 1983. Initially Section 58 applied only to patients detained after that date under the new Act. Because the Act allows for an assessment period for medication of three months before the procedures of Section $\mathbf{5 8}$ are enforced, requests for second opinions during the first three months were confined to treatment with electroplexy. By 1 January 1984 some patients detained under the 1983 Act required second opinions in respect of treatment with medication. Finally, on 1 April (Schedule 5) all detained patients who were originally admitted under the $1959 \mathrm{Act}$, and were still detained, became subject to the new procedures. In order to prevent a flood of requests on 1 April, RMOs were requested to spread requests for second opinions over the preceding months.

This phased implementation clearly affected the nature of the patients presenting in different periods. For the first three months of operation second opinions were provided only by 
the medical members of the Commission. Early experiences were subject to much anecdotal debate within the Commission in an attempt to obtain uniformity of practice. With time a further body of senior psychiatrists, after appropriate induction, were added to the ranks of the approved doctors.

\section{The study}

The Southern Region of the Commission extends southeast of a line drawn between the Wash, through mid Wales to the West coast and comprises $35,635,000$ persons. It contains one Special Hospital.

A sample of 100 cases was drawn from the Southern Region (SR) requests by taking every sixth case on the register. Of all SR requests, about twenty did not result in a visit because the patient was found not to be detained or because he consented before the consultation took place. If the sampling procedures fell upon such a case the next actual visit was taken.

Between 30 Sepember 1983 and 24 May 1984, 670 requests for second opinions were received in the Southern Region office. The visits were undertaken in sixty-one hospitals by thirty-five approved doctors of whom seven were medical Commissioners. Individual hospitals required one to four patients to be visited within the period of the study and individual approved doctors participated in one to thirteen consultations. With no allowance for holidays, there were 22-23 requests to the SR office per week, or 4-5 per working day.

\section{The clinical picture}

The age range of the sample was from 21 to 85 years, with a mean of $\mathbf{5 2}$ years. A strong association was found between (a) age over 60 , female, a diagnosis of depression and treatment with electroplexy (often with drugs too) and (b) age under 60. male, a diagnosis of schizophrenia and treatment with drugs for over three months (and often for much longer periods).

It was the common experience of ADs that, while there was little difficulty in finding an appropriate nurse with whom to discuss the patient, there was much greater difficulty in securing the services of a person who was neither a doctor nor a nurse. For this reason the study concentrated upon this second person rather than the nurse.

That six persons were consulted who had known the patient for less than a day confirmed a general impression that it was often necessary to involve a person at the eleventh hour. Six may not be a large number out of 100 , but extrapolated to the Southern Region as a whole, represents forty patients in an cight-month period. A further ten persons (10 per cent) had known the patients for up to a week; often they were the admitting social worker. In seventy-four patients ( 82 per cent of the relevant sample), the patients had been known for more than a week and thirty-two ( 36 per cent) for more than a year. The professionals most commonly involved were social workcrs (60 per cent). the remedial professions, most usually occupational therapists (28 per cent), and clinical psychologists ( 9 per cent).

Section 62 provides for emergency treatment, but to extend treatment excessively under this section would be an abuse and no reason for not implementing the formalities of Section
58 as soon as possible. In six of the present series of 100 cases, Section 62 had been invoked to give electroplexy before consultation with the AD occurred. (Five occurred in the early days of the procedures.) A minimum number of treatments (one to two) had been given in four cases, but one had been given four treatments.

Only six cases were mentally impaired, but in two an overlaying psychosis (schizophrenia and depression, respectively) was the prime reason for treatment. All bar one required extended drug treatment. The patient requiring ECT was the one with an overlaying depression. Without exception they were incapable of giving consent.

The forms of detention are shown in Table I. (Informal patients were visited in error.) The majority of patients ( 80 per cent) were detained on clinical grounds, but the small number of offenders (seventeen) are of interest.

The distributions of the diagnoses and the two major treatments according to the Section employed are shown in Tables II and III respectively. Diagnosis overall was unrelated to the Section used. But, as regards treatment, patients detained under Part 2, Section 2 were always given ECT while those under Section 3 were given ECT and extended medication in equal numbers. Offenders under Part 3 were treated entirely with medication. There is no legal reason for this and the decision must have been made on clinical grounds.

The distribution of offenders detained under Part 3 of the Act between Special and local mental hospitals in the Southern Region is shown in Table IV. Most of the consultations on patients detained under Part 3 occurred in mental illness hospitals (some housed interim secure units). Few con-

TABLE I

Types of detention order

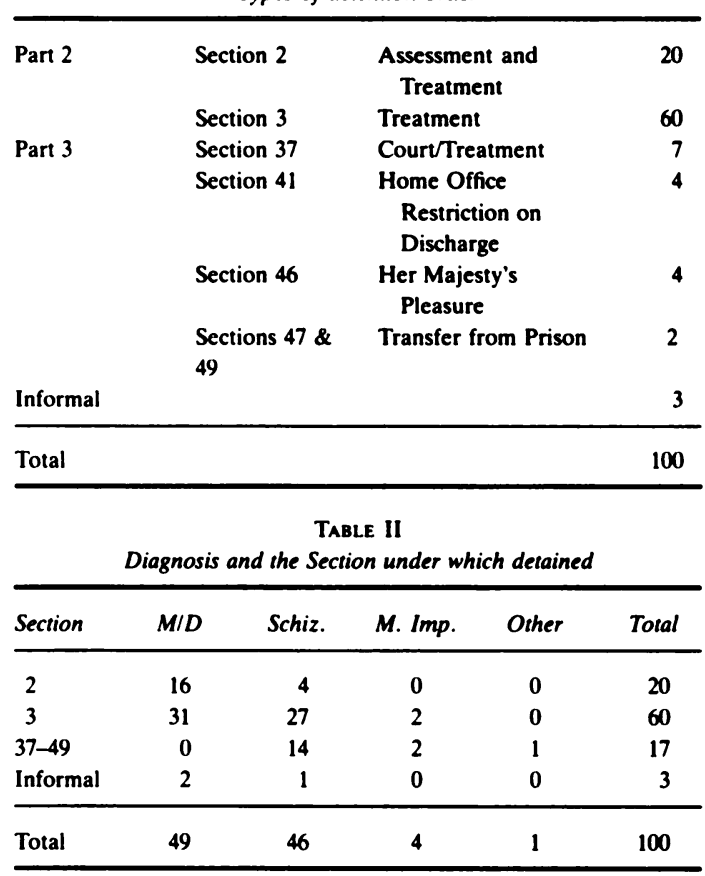


TABLE III

Treatment and the mode of detention

\begin{tabular}{|c|c|c|c|c|}
\hline & & $E C T$ & Medication & Total \\
\hline \multirow[t]{2}{*}{ Part 2} & Section 2 & 20 & $\mathbf{0}$ & 20 \\
\hline & Section 3 & 30 & 30 & 60 \\
\hline Part 3 & Sections $37-49$ & 0 & 17 & 17 \\
\hline Informal & & 2 & 1 & 3 \\
\hline Total & & 52 & 48 & 100 \\
\hline
\end{tabular}

TABLE IV

The Special Hospital and offenders detained under the Act

\begin{tabular}{lcccc}
\hline & \multicolumn{4}{c}{ Other hospitals } \\
\cline { 3 - 5 } Section & $\begin{array}{c}\text { Special } \\
\text { hospital }\end{array}$ & $\begin{array}{c}\text { Mental } \\
\text { illness }\end{array}$ & $\begin{array}{c}\text { Mental } \\
\text { handicap }\end{array}$ & Total \\
\hline 37 & 0 & 6 & 1 & 7 \\
41 & 1 & 2 & 1 & 4 \\
46 & 2 & 2 & 0 & 4 \\
$47 \& 49$ & 0 & 2 & 0 & 2 \\
\hline Total & 3 & 12 & 2 & 17 \\
\hline
\end{tabular}

sultations on offenders occurred in hospitals for the mentally handicapped. The phased implementation of these procedures over the period of study requires some examination of how this phasing has influenced the results before any general validity can be assumed.

The sample was recorded sequentially in four blocks of twenty-five cases starting with the first request. As expected, consultations in the first block were concerned almost exclusively with ECT. The second block incorporated extended medication and the third recorded the rush to catch up with the backlog of patients detained under the 1959 Act. The fourth block spanned a period when the rush was over and patients were evenly distributed between the two forms of treatment. The duration of the blocks, with some rounding, was, in sequence: four months, one and a half months, one week and one month. The short third block illustrated the hectic catching-up period and both the extended period of the fourth block and the even balance of treatments suggest that the pattern of referrals is now settling down.

\section{Anecdotes}

On two early visits the patient was found not to be detained when the AD arrived. This was as often due to a failure to understand that the new practices applied only to detained patients as to frank errors in detention procedures, although these were also seen. In one case the patient was regraded to informal status as a result of the consultation.

Unusual 'neither a doctor nor a nurse' persons reported were an occupation officer, a bank manager (presumably the hospital bank!) and an undecipherable ' $n$...'

In two cases the AD secured the patient's consent to treatment when the RMO had failed. All other certificates were that 'the treatment should be given'. In one case the procedures were overdue at the time of the request, but in another it was reassuring to see that an interpreter had been used before the patient was deemed incapable. In yet another a certificate was refused because the patient was too ill physically. He died a few days later.

In all, significant legal or clinical changes occurred in the patient's care in six cases out of $\mathbf{1 0 0}$.

\section{Comment}

The clinical data presented here are relatively crude, being limited by the brief nature of the report forms, but the pattern makes general clinical sense.

The practices studied have the force of law and cannot easily be changed. Nevertheless their effectiveness and efficiency bear comment. A precise cost benefit analysis is not possible. Experience suggests that the cost of the exercise in time, fees and expenses is considerable. The number of treatment plans changed by the procedures is small, but not insignificant (6 per cent). Additionally, by encouraging the RMOs to consider specific treatments and broader treatment plans in advance of the consultation the effect may be greater than the number of actual revisions suggests. In a well-run service the incidence of differences of opinion with the AD might be expected to be low. Finally, if public confidence is maintained in how the Mental Health Services administer treatments that some consider to be controversial, there will be a worthwhile gain.

There is a high incidence of depressed elderly women in this series and anecdote suggests many were severely disturbed. The importance of this group in clinical practice and resource allocation is stressed.

The detained mentally impaired do not seem to present a great numerical problem where consent to treatment is concerned, but how these issues are managed in the greater number of those receiving informal treatment is another matter.

Why it is that some patients are thought to be incapable of giving consent (other than by reason of mental impairment) and other patients refuse is not clear, yet RMOs and ADs make the distinction with great regularity-for a clinical analysis of the issues, see Applebaum and Gutheil.'

It is to be hoped that in due course the Mental Health Act Commission will be able to allocate sufficient resources to make a more detailed analysis of second opinions under both Section 58 and Section 57 (psychosurgery and hormone implants).

\section{ACKNOWLEDGEMENTS}

My thanks are due to the Mental Health Act Commission for permission to publish, to Malcolm Rowlands and Pat Nicholls of the Mental Health Act Commission for assistance with the data, and to Gail Robertson and Lynda Henneman for the processing.

\section{RefERENCE}

'Applebaum, P. S. \& Guthell. T. G. (1982) Clinical aspects of treatment refusal. Comprehensive Psychiatry, 23, 560-6.

The views expressed are personal and do not necessarily reflect the views of the Mental Health Act Commission. 